\title{
BÉCQUER. ESTÉTICA DEL BORRADOR
}

\author{
Luis CAPARRÓS ESPERANTE*
}

Colección de proyectos, argumentos, ideas y planes de cosas diferentes que se concluirán o no según sople el viento.

G. A.B.

Yo las quemé en memoria y en honor del divino Gustavo Adolfo. ANTONIO MACHADO

Fonction des brouillons dans la création de l'écriture de Bécquer. Le pré-texte qui s'objective dans ces écrits confirme ses idées poétiques sur le rôle (relatif) de la mémoire, la nécessité d'une "consciencieuse composition "... En revanche, pas d'abîme "entre le monde de l'idée et celui de la forme " : réexamen et réévaluation du Libro de los Gorriones et de sa disposition textuelle dans cette perspective.

Función de los borradores en el proceso becqueriano de escritura. El plano antetextual, objetivado en esos papeles, refuerza las conclusiones de su poética : papel (relativo) de la memoria, necesidad de una " concienzuda composición "... Pero niega el supuesto abismo " entre el mundo de la idea y el de la forma $"$. Reconsideración y reivindicación del Libro de los gorriones y de su orden textual a esta luz.

Role of drafts in Bécquer's writing process. The pretextual level, as seen in those papers, upholds the conclusions of his poetical theory : (relative) part of memory, the need of a " concienzuda composición "... But it denies the assumed abyss between " el mundo de la idea y el de la forma $n$. Reconsideration and vindication of Libro de los gorriones and its textual order under this point of vue.

Mots-clés : Bécquer - Brouillons - Poétique - Processus d'écriture.

\section{I. - ESBOZOS, PLANES, NOTAS, BORRADORES}

En el taller del escritor, en cajones apartados de la vista o en anodinas carpetas sin rótulo, se aprietan cuadernos con notas. Son bocetos y borradores, ideas que se conluirán o no, que serán trabajados o reconocidos

- Universidade da Coruña, Facultade de Filoloxía, Dept. de Filoloxía Española, Campus de Elviña, s/n. 15071 La Coruña. España. 
según sople el viento. Así ha sucedido y así sucederá en todos los casos, hablemos de un romántico o hablemos de un clásico, sea en 1605 o sea en 1925. No es algo llamativo. Tampoco es cuestión de cantidad. La obviedad de su existencia es independiente de que se conserven más o menos papeles.

El destino final de esos papeles, sin embargo, es asunto del mayor interés para el escritor... y para el filólogo. La atración de las llamas es permanente, tanto más cuando se sospecha el husmeo ajeno. Aunque no todos los borradores son iguales. Como si de un invernadero se tratase, el escritor cultiva en su taller plantas en diferente grado de desarrollo y de maduración. Algunas son de crecimiento rápido, como ciertas flores de temporada. Otras recuerdan la añosa consistencia de un castaño. Otras son plantas de propiedades inconfesables. ¿Cuándo debe cortarse el tallo ? ¿Cuándo están hechas? ¿Cuándo malogradas? No hay una respuesta fácil. A veces, según qué escritores, esa decisión puede llegar a ser angustiosa. La persistencia de esa angustia tiene su prueba mayor en Virgilio, cuando atisba la posibilidad de morir antes de dar término a la Eneida y ruega que, si eso sucediese, el poema inconcluso se arroje al fuego. Novecientos años más tarde, Kafka vuelve a representar con igual sinceridad la viejísima escena del sacrificio.

No conservamos demasiados papeles personales de Bécquer, por las razones que sea, que poco importa para el caso. Está claro que debía de tener, como cualquier otro escritor, una buena cantidad de inéditos en barbecho. Cada cierto tiempo aparece uno nuevo, para confirmarlo'. Lo que sí importa es que él, además de guardarlos, llama con frecuencia nuestra atención sobre ellos. Ahí está una primera clave. Al final, cuando le amenaza la muerte, no ordenará quemar su obra inédita. Representa la escena virgiliana, sí, pero solamente con una cartas que, de conocerse, pudieran ser

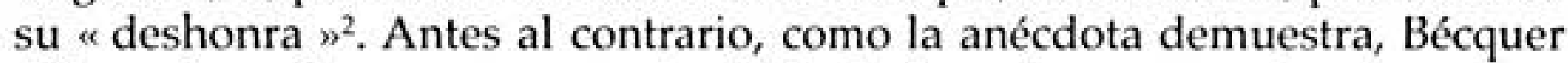
diferencia perfectamente entre lo vital y lo literario, y pretende asegurar su obra lírica.

No es extraño. Pensemos en lo poco que quedaría de su trabajo si todos aquellos materiales inéditos hubiesen parado en el fuego o en el olvido. Su brevísima obra lírica madura y madura en los borradores, sin encontrar el momento de salir a la luz. En vida publica solamente catorce poemas.

1. Los más recientes han sido rescatados por Leonardo Romero Tobar : Nuevos autógrafos becquerianos ", Insula, 528 (1990), p. 16-18, y Gustazo Adolfo Bécquer. Autógrafos jutveniles (Manuscrito 22.511 de la Biblioteca Nacional), Puvill, Barcelona, 1993.

2. "Me muero - decía -. Sabéis que no soy pretencioso ; pero si es posible publicad mis versos. Tengo el presentimiento de que muerto seré más y mejor leído que vivo." Dos días antes de morir, cuando ya apenas podía hablar, hizo que Ferrán le diera un paquetito de papeles atados con una cinta azul, y sacando trabajosamente un brazo de entre las ropas de la cama, los quemó en la luz de una bujía que ardía en la mesa de noche " (Florencio Moreno Godino, "Semblanza de Gustavo Adolfo Domínguez Bécquer ", La llustración Artística, 4 de febrero de 1895, p. 115-116). Cito aquí por La Ilustración de Madrid. Textos de Gustavo Adolfo Bécquer acompañados de dibujos de Valeriano Bécquer, publicados durante los años 1870 y 1871 en * La llustración de Madrid ", ed. María Dolores Cabra Loredo, El Museo Universal, Madrid, 1983, p. 265. 
Alguno llega a conocer varias impresiones, sin que se sintiese obligado a tirar de la carpeta de inéditos que, sin ninguna duda, guardaba. Es fácil concluir que le costaba trabajo dar por terminada la fase de lima. "Antes repetirme que arrepentirme ", es probable que pensase. ¿ Se puede hablar de angustia en este caso?

La lucha de Bécquer con la palabra ha sido leída de modo excesivamente literal. Es casi inevitable rendirse a las bellísimas sugerencias de la Introducción sinfónica, cuando describe la desasosegante inmaterialidad de sus creaciones mentales :

Conmigo van, destinados a morir conmigo, sin que de ellos quede otro rastro que el que deja un sueño de la media noche que a la mañana no puede recordarse. En algunas ocasiones y ante esta idea terrible se subleva en ellos el instinto de la vida y agitándose en terrible aunque silencioso tumulto buscan en tropel por donde salir a la luz, de las tinieblas en que viven. Pero, ; ay !, ; que entre el mundo de la idea y el de la forma existe un abismo que sólo puede salvar la palabra y la palabra tímida y perezosa se niega a secundar sus esfuerzos ! ${ }^{3}$

Entre el mundo de la idea y el de la forma existe un abismo, claro está. Tan claro como que el escritor, para salvarlo, tiende frágiles pasarelas, puentecillos provisionales que ayudan a salvar el vértigo de la escritura sobre el blanco abismo del papel. Eso son los borradores.

"Tal vez muy pronto tendré que hacer la maleta para el gran viaje ", escribe en la Introducción sinfónicat. ¿Significa eso que deba quemar sus borradores ? Todo lo contrario. Queda tiempo, pensaría, sumergido en el breve paraíso toledano, oyendo a los niños jugar afuera, con el libro de cuentas abierto sobre la mesa. Ese libro es el Libro de los gorriones, donde ya ha escrito la Introducción sinfónica. Cuando muera, podría pensar - la muerte no tiene fecha -, una parte de sus imaginaciones no se irá a perder con él mismo "en los desvanes del cerebro ", sino en otros desvanes más duraderos.

(Permítaseme un paréntesis que en realidad no es tal, sino aclaración de principio : el libro mayor de la lírica española decimonónica se quedó en estado de borrador - aunque esto disguste profundamente a los sucesivos editores del texto. Un borrador en limpio, esto es, en un estado superior de maduración.)

Vamos teniendo abundantes ejemplos del modo sistemático en que trabajaba Bécquer antes de dar por bueno un texto. Romero Tobar, al publicar no hace muchos años dos autógrafos suyos - y en concreto un esbozo de la reseña de La soledad - subrayaba cuanto hay de fábrica, de lima y trabajo artesanal :

Este esbozo, caso de ser una redacción previa a la del artículo de El Contemporíneo, permitiría establecer algunas cautelas frente a las afirmaciones del poeta, luego

3. Gustavo Adolfo Bécquer, Libro de los gorriones, ed. María del Pilar Palomo, Cupsa (Hispánicos Planeta, 10), Madrid, 1977, p. 5-6.

4. Ibidem, p. 7. 
recogidas por comentaristas y exégetas, y que abundan en el énfasis puesto en el trabajo mental del artista frente a la disciplina exterior que significan los borradores y apuntes 5

La evidencia de la lima y el orden no desmentiría en ningún caso la necesidad sentida de que el texto brote de esa germinación mental, única vía que concibe Bécquer para poder transmitir auténtico calor vital a sus escritos. Es lo que señala, como un ejemplo entre muchos otros posibles, en la segunda de sus cartas Desde mi celda:

\begin{abstract}
¡Qué sé yo!, escenas sueltas de no sé qué historias que yo he oído o que inventaré algún día ; personajes fantásticos que, unos tras otros, van pasando ante mi vista, y de los cuales cada uno me dice una palabra o me sugiere una idea ; ideas y palabras que más tarde germinarán en mi cerebro y acaso den fruto en el porvenirs.
\end{abstract}

Si eso es cierto, que lo es, eso no es todo. El párrafo citado resalta la perspectiva embellecedora de la actividad del artista, donde aún gravitan ciertos tópicos románticos - aunque en absoluto universales - acerca de la inspiración o de la maduración limpia y etérea en el cerebro. La realidad es otra y tiene más que ver con el pulso antes material que ideal planteado por la escritura. La angustia de la escritura atenaza a Bécquer, como a tantos artistas contemporáneos expuestos a la intemperie de una época sin reglas. Se ha comentado infinitas veces desde la perspectiva de su poética y no es cosa de repetirlo ahora ${ }^{7}$. También lo podemos deducir fácilmente de lo anterior, desde esta otra perspectiva más inmediata, más práctica, menos elevada. En el paréntesis toledano encuentra tiempo para reescribir una vez más sus pocos y breves poemas. Son mucho, sin embargo, para quien se ha descrito en alguna ocasión como « atado por la conciencia del deber a una silla, frente a una mesa, donde el papel parece mofarse de nuestra esterilidad y nuestra impotencia con su insultante y deslumbradora blancura $n^{8}$.

Esa queja ante la página en blanco tiene varias caras, no todas aptas para una lectura en clave de artista como la que acabo de hacer. La mayor parte de ellas brotan, por el contrario, de su vertiente periodística, casi siempre alimenticia, algo que alcanza incluso a las cartas Desde mi celda, donde aún recuerda " ese océano sin fondo, ese abismo de cuartillas que se llama un periódico, especie de tonel que, como el de las Danaidas, siempre se le está echando original y siempre está vacío ${ }^{9}$. En Desde mi celda, como en la mayoría de las Leyendas, Bécquer consigue atar a un mismo impulso la necesidad y el placer, el periodismo y el arte. Pero cuántas y cuántas cuartillas anónimas habrá entregado, entre tanto, a las prensas de El

5. Leonardo Romero Tobar, * Nuevos autógrafos... *, p. 17.

6. Gustavo Adolfo Bécquer, Desde mi celda, ed. Dario Villanueva, Castalia (Clásicos Castalia, 138), Madrid, 1985, p. 108-109.

7. « $;$ El orden! - escribe en las Cartas literarias a una mujer - ; Lo detesto, $y$, sin embargo es tan preciso para todo !... . (Obras completas, 13 ed., Aguilar, Madrid, 1981, p. 625).

8. Gustavo Adolfo Bécquer, * Caso de ablativo (sobre la inauguración de la línea completa del ferrocarril del Norte) \#, en Obras completas, p. 951.

9. Desde mi celda, p. 87. 
Contemporáneo. La exigencia inmediata de original no deja tiempo para borradores ni para arrepentimientos. Al comienzo de la segunda carta se presenta a sí mismo, no como poeta en exquisito trance creativo, sino como forzado de la pluma : "Queridos amigos : Si me vieran ustedes en algunas ocasiones con la pluma en la mano y el papel delante, buscando un asunto cualquiera para emborronar catorce o quince cuartillas, tendrían lástima de $m i ́ n{ }^{10}$. Esto, desde luego, no lo escribe el poeta que revisa por enésima vez sus poemas. Esa angustia de la página en blanco que nos describe ahí tiene poco o nada de mallarmeano.

\section{II. - PUENTES SOBRE EL ABISMO DEL PAPEL EN BLANCO}

Un borrador, por su condición de puente entre la intuición inicial y la escritura final, es el lugar del combate con la palabra, su campo de batalla. Las poéticas de autor no quedan al margen de esa lucha cuerpo a cuerpo, si son realmente sinceras, si son - Eco lo dice - " el programa operativo que una y otra vez se propone el artista, el proyecto de la obra a realizar como lo entiende explícita o implícitamente el artista $"^{11}$. En fin, las poéticas tienen un papel principalísimo para el artista contemporáneo como medio de objetivación y resolución de dudas y problemas, acaso en igualdad de condiciones con el ejercicio de la crítica, la cual no deja de ser una forma elusiva y objetivadora de construirse una poética.

En ese sentido, las poéticas van estrechamente unidas a la noción más dinámica de obra en marcha, de work in progress, y por lo mismo, es posible e incluso conveniente acercarlas a la plasticidad de los borradores. El texto acabado de una poética, cuando el autor así lo determina, deja en ese momento de ser borrador y acaso deja también de ser poética en el sentido, arriba indicado, de proyecto abierto para la producción de textos. En cualquier caso, la poética de artista - oficial, pública, cerrada, seria - se corresponde casi siempre con un sustrato inferior construido por opiniones, notas al margen, dudas, deseos, que a duras penas nos permiten hablar de poética e invitan a pensar en términos de estética, entendida ésta en el sentido dieciochesco, es decir, básicamente como gusto. Esa poética menor, utilitaria, está ligada naturalmente a facetas que se corresponden muy bien con el estrato antetextual constituido por los bocetos, o el cuaderno de notas del periodista, el papel de grano del dibujante, las hojas volanderas de las cartas, etc. En este plano, el inevitable tono pontifical de la poética se disuelve en humor, en ironía, se hace relativo, y sobre todo, liga la experiencia de la escritura a experiencias biográficas reales y concretas, vividas.

Hay una perspectiva intermedia. El periodista y el artista hallan un espacio común en el bloc de notas. El artista puede comenzar "Tres fechas " con esta indicación : "En una cartera de dibujo que conservo aún llena de ligeros 
apuntes, hechos durante algunas de mis excursiones semiartísticas... ${ }^{12}$. El reportero, en trance de informarnos de la inauguración de la vía férrea entre Madrid y el norte, nos describe así su cartera :

En la cartera de viaje, y escritas con lápiz, tengo unas cuantas notas hechas en el camino, descosidas, incorrectas, casi sin ilación, como tomadas al escape para fijar las impresiones del momento, pero que si juntas no forman un artículo con sus requisitos de plan, de gradación y enlace, darán seguramente una idea más aproximada que cualquiera otro género de trabajo de la rapidez con que los objetos y los pensamientos que estos engendraban herían los ojos y la imaginación ${ }^{13}$.

Llamo la atención del lector sobre las extraordinarias similitudes de este pasaje periodístico con otros donde Bécquer analiza, en clave artística o metapoética, su peculiar experiencia creativa, incluso con las mismas palabras. Precisamente, la distancia entre la experiencia artística e ideal que evocan esas palabras - con su regusto neoplatónico - y la experiencia concreta, nada sublime, a que aluden, puede servirnos a un mismo tiempo como eficaz contrapeso a cualquier exageración erudita y como prueba del sincero arraigo de esas ideas en Bécquer. En este caso, las notas a lápiz son mencionadas expresamente como vínculo mnemotécnico entre la sensación física producida por los objetos, los pensamientos despertados por ella y, finalmente, la imaginación, que cabría tildar - more romántico - de imaginación creadora ${ }^{14}$. Las notas son "jeroglífico " que sirve "para fijar las impresiones del momento ${ }^{15}$. O bien, impresiones de otro calado. Volvamos a Desde mi celda :

No pueden ustedes figurarse el botín de ideas e impresiones que para enriquecer la imaginación he recogido en esta vuelta por un país virgen y aún refractario a las innovaciones civilizadoras. Al volver al monasterio, después de haberme detenido aquí para recoger una tradición oscura de boca de una aldeana, allá para apuntar los fabulosos datos sobre el origen de un lugar o la fundación de un castillo, trazar ligeramente con el lápiz el contorno de una casuca medio árabe, medio bizantina, un recuerdo de las costumbres o un tipo perfecto de los habitantes, no he podido menos de recordar el antiguo y manoseado símil de las abejas que andan revoloteando de flor en flor y vuelven a su colmena cargadas de miel ${ }^{16}$.

El «botín de ideas e impresiones " no está descrito en términos exclusivamente psicológicos, sino que una vez más es perfectamente material : un apunte al vuelo de tradiciones vinculadas a lugares reales, la transcripción de relatos oídos de viva voz, esbozos a lápiz... Las notas parecen apuntar a su utilización para futuras leyendas, pero aún no existe " plan, gradación y

12. *Tres fechas ", en Obras completas, p. 349.

13. * Caso de ablativo ", en Obras completas, p. 953. El reportaje apareció como anónimo en El Contemporáneo, el 21 de agosto de 1864.

14. Con todas las salvedades, podría también ponerse en relación con el sensacionismo dieciochesco, que arrastra de su molde clasicista sevillano. Vid. el polémico artículo de Philip W. Silver, « Bécquer sublime, entre dieciochesco y symboliste n, Insula, 528 (1990), p. 11-12. En él, y como rasgo peculiar suyo, ambas vertientes se encuentran sin demasiado conflicto.

15. * Caso de ablativo $*$, p. 953.

16. Desde mi celda, p. 135. 
enlace ". La actitud de base es idéntica a la anterior. En uno y otro caso, además, la impasibilidad del observador es garantía de un " botín " realmente útil. Quisiera entonces

disponer de la calma y el aplomo necesarios para sacar un librito de apuntes en la situación más crítica y apuntar en él cuanto me impresiona o me importa saber más tarde. Yo no me canso de admirar a [...] los ingleses, que en medio de una conflagración general, y en el filo de una espada, son capaces de hacer un croquis o apuntar una nota con la impasibilidad y la sangre fría admirable del mundo ${ }^{17}$.

De nuevo nos encontramos con la versión en humilis stylus - digámoslo en pedante - de conceptos que en otros lugares, como las Cartas literarias a una mujer, adquieren, si no un calado teórico (relativamente) mayor, sí una mayor ambición descriptiva de la experiencia artística. En las Cartas literarias..., como se recordará, el momento de la escritura exige de él estar "puro, tranquilo, sereno, y revestido, por decirlo así, de un poder sobrenatural ", frente a la imagen del " genio ebrio de sensaciones y de inspiración ${ }^{18}$.

En realidad, Gustavo tiene muy próxima la experiencia plástica y vital de su hermano Valeriano, si no la suya propia en el mismo terreno. En ese ámbito previo a la formalización expresiva, en ese plano utópico que suele él mismo denominar como mundo de la Idea, no cuentan demasiado las diferencias materiales entre literatura y artes plásticas. El tópico ut pictura poesis está bien arraigado en su sensibilidad ${ }^{19}$. Ya es muy elocuente que en buena parte de sus borradores conservados se entremezclen versos, palabras y dibujos bajo una misma voluntad mnemotécnica. Recuérdese, como ejemplo mayor, el borrador de la rima " En la imponente nave " $(74, \mathrm{LXXVI})$, conservado en el Museo de Arte Decorativo de Buenos Aires, de cuya génesis nos dejó un expresivo recuerdo Moreno Godino ${ }^{20}$. Otro sesgo de lo mismo lo ofrece la leyenda Los ojos verdes, donde llama la atención el que los ojos del título sean presentados desde su faceta más plástica, para ofrecernos en seguida el relato verbal como boceto de una posible pintura :

De seguro no los podré describir tal cual ellos eran : luminosos, trasparentes como las gotas de la lluvia que se resbalan sobre las hojas de los árboles después de una tempestad de verano. De todos modos, cuento con la imaginación de mis lectores para hacerme comprender en este que pudiéramos llamar boceto de un cuadro que pintaré algún día ${ }^{21}$.

17. * Caso de ablativo n, p. 967.

18. Obras completas, p. 622 y 623.

19. Véase un buen marco teórico para esa relación en la ponencia de Darío Villanueva, * Ut pictura poesis : La creación artística de los Bécquer ", en Jesús Rubio Jiménez, ed., Actas del Congreso * Los Bécquer y el Moncayo ". Celebrado en Tarazón y Veruela. Septiembre 1990, Institución Fernando el Católico y Centro de Estudios Turiasonensis, Ejea de los Caballeros, 1992, p. 93-113.

20. Puede verse ese borrador en Rafael Montesinos, Bécquer. Biografia e imagen, RM, Barcelona, 1977, p. 197 y 199. Acerca de él, escribía Florencio Moreno Godino en la semblanza antes citada : "Bécquer dibujaba antes de escribir un esbozo de la composición pensada o cuyo tema estaba pensando, y el cual le proporcionaba a veces el dibujo que delineaba inconscientemente y como al acaso. En una ocasión, sin intención previa, trazó un sepulcro gótico y sobre él la estatua yacente de una mujer ; empezo a hacer el cimiento de la ojiva que había de cubrirle, y esto le sugirió la idea de una de sus composiciones poéticas, que al coleccionar sus versos se puso la última a indicación mia * (La llustración de Madrid..., p. 263).

21. Gustavo Adolfo Bécquer, Leyendas, ed. Joan Estruch, Crítica (Biblioteca Clásica, 99), Barcelona, 1994, p. 125. 
En uno y otro caso, se trate de palabras o se trate de plástica, la sensibilidad se debe alimentar en la vida, se debe " copiar del natural "-según él repite -, y esto resulta ser exigencia fundamental para quien no quiere caer en el manierismo 22 .

Por ello, cuando habla en la citada carta segunda de recuerdo en germinación, no debemos tomarlo de un modo demasiado literal, en su dimensión solamente psíquica. El recuerdo se fija antes en boceto, en apunte, esto es, en un primer estado material y sensible, ligado a una experiencia igualmente sensible. Sin embargo, y esto es lo que realmente importa, venga o no el recuerdo a través del boceto, jamás se confundirá con la obra hecha, rematada, con su " concienzuda composición ". Así lo escribe en " La salida de la escuela ", al comentar de nuevo un grabado de Valeriano:

Cuatro líneas en la cartera de apuntes, un rasgo que fija el carácter especial de las figuras o una mancha que recuerda el juego de luz o la disposición del fondo son el punto de partida basado en el natural, que sirve más tarde para la concienzuda composición de un cuadro ${ }^{23}$.

Hay, por ello, mucha distancia y mucho trabajo entre las notas y el escrito final. En la Introducción sinfónica se desata la tensión angustiosa, pues la muerte amenaza " antes que su Creador haya podido pronunciar el fiat lux que separa la claridad de las sombras $»^{24}$. Al final del reportaje sobre el ferrocarril del norte volvemos a encontrar la misma actitud de fondo, si bien ahora diluida en humor:

¡ Jesús ! ¡ Jesús ! ¡ Yo no sé cómo me las voy a gobernar para poner en limpio tanta divina cosa como llevo apuntada en la cartera $!_{i} Y$ decir que mañana tengo que emprender esa obra, más colosal que hacer la luz en el caos!

Francamente, dan ganas de no divertirse, por no tener que contar al público en qué y cómo se ha divertido uno ${ }^{25}$.

\section{III. - LA PEREZA ACTIVA, ESTO ES, LA POESÍA}

La alusión anterior a la pereza merece comentario aparte. Ya en las cartas Desde mi celda alude a «la enfermedad y su natural propensión a la vagancia ${ }^{26}$. Es cierto que reaparece la idea en varios escritos becquerianos, e incluso un texto suyo lleva ese título, "La pereza ". En él hallamos una curiosa versión - humilis y perezosa - de la lucha con la palabra :

22. Así lo escribía Gustavo, en la reseña póstuma a la obra de su hermano : « La costumbre de estar siempre apuntando del natural hacia que no se amanerase nunca y que hubiese en sus composiciones un sello grande de verdad "(Obras completas, p. 1213).

23. "La salida de la escuela *, anónimo en El Museo Universal, 15 de octubre de 1865 . Recogido en Obras completas, p. 1127.

24. Libros de los gorriones, p. 7.

25. "Caso de ablativo ", p. 968.

26. Desde mi celda, p. 104 
Algunas veces, la Pereza, esa deidad celeste, primera amiga del hombre feliz, pasa a nuestro lado y nos envuelve en la suave atmósfera de languidez que la rodea, y se sienta con nosotros y nos habla ese idioma divino de la transmisión de las ideas por el fluido, para el que no se necesita ni aun tomarse el trabajo de remover los labios para articular palabras ${ }^{2}$.

Es muy curioso observar cómo en ese artículo, siempre en clave irónica - es decir, con un fondo de verdad -, se asocia la «forma material y grosera " en que acaban conformados ideas y ensueños a las cotizaciones en "el mercado público ». Una vez más, refuerza la separación precisa entre la esfera íntima y la pública. De ahí que

Santas ilusiones, sensaciones purísimas, fantasías locas, ideas extrañas, todos los misteriosos hijos del espíritu son, apenas nacen, cogidos por la materia, su estúpido consocio, y expuestos, desnudos, temblorosos y avergonzados, a los ojos de la multitud ignorante.

Yo quisiera pensar para mí y gozar con mis alegrías, y llorar con mis dolores, adormecido en los brazos de la pereza, $y$ no tener necesidad de divertir a nadie con la relación de mis pensamientos y mis sensaciones más secretas y escondidas ${ }^{23}$.

Frente al frenesí de las redacciones, donde la escritura tiende a convertirse en mercado, Bécquer apuesta por algo semejante a aquel ocio productivo de que hablaban los institucionistas. La pereza, en concreto, puede alimentar la fantasía, o por lo menos, eso escribe en el artículo " Haciendo tiempo " :

¡Cuántas grandes ideas, cuántos útiles descubrimientos habrán nacido o se habrán desarrollado en uno de esos momentos en que parece que el hombre se entrega al supremo placer del dolce far niente ! Porque si la voluntad puede reducir al cuerpo a la inacción, no puede, del mismo modo, cortar los vuelos de la fantasía que a veces produce sus mejores frutos cuando está menos excitada, como son mejores los frutos que el árbol da espontáneamente ${ }^{29}$.

En fin, la pereza es un motivo típico de la bohemia decimonónica, que atraviesa a los decadentistas y se remansa en Cernuda mismo ${ }^{30}$. No olvidemos en este contexto a Augusto Ferrán, tan bohemio él, que publica $\mathrm{La}$ pereza en 1871, a poco de morir su íntimo amigo Bécquer. En el poema inicial de ese libro se encuentran ideas muy semejantes a las que acabamos de leer :

27. * La pereza , en Obras completas, p. 658.

28. Ibidem, p. 659. Recuérdese la célebre frase de Charles Baudelaire : « Qu'est-ce que l'art ? Prostitution " (Mon caur mis à nu, en CEuvres complètes, Seuil, Paris, 1968, p. 623). Claro que para Baudelaire la prostitución no sugiere algo negativo, en principio. $Y$, si se me permite decirlo, Bécquer se siente en párrafos como éste perfectamente solidario del gremio susodicho.

29. "Haciendo tiempo ", en Obras completas, p. 673. Fue publicado en El Contemporáneo. Pageard considera que el artículo no es de Bécquer, sino de Pongilioni ( $\propto$ Espíritu y tareas de la investigación becqueriana ", en las citadas Actas del Congreso « Los Bécquer y el Moncayo *, p. 217). Lo sea o no, el ejemplo es igualmente válido para el marco ambiental desde el que lo contemplamos.

30. Véase ahora Bohemia y literatura (De Bécquer al Modernismo), eds. Pedro M. Piñero y Rogelio Reyes, Universidad de Sevilla, Sevilla, 1993, p. 27-49. Cernuda insiste en ese tópico : " Ahora levántate y marcha a la playa. Por esta mañana ya has trabajado casi suficientemente en tu ocio " (Variaciones sobre tema mexicano, en Poesía completa, Siruela, Madrid, 1993, p. 639). 
Hay una pereza activa que mientras descansa piensa, que calla porque se vence, que duerme pero que sueña.

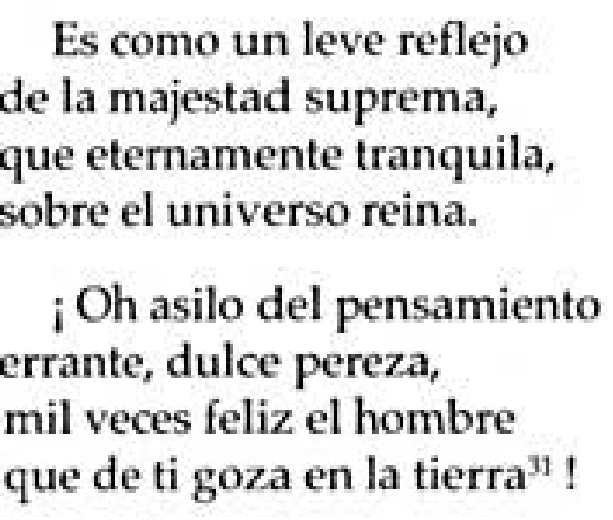

Pero con esto nos hemos alejado aparentemente del tema. ¿Significa lo anterior que Bécquer no acaba sus obras y las deja en boceto por pura pereza ? Nada más lejos de la realidad. Bécquer, inmerso en la vorágine del noche a noche de las redacciones, de la lucha por la vida, añora la posibilidad de tener tiempo para sí, lo cual significa tiempo para viajar y enriquecer el espíritu, y tiempo para escribir sin un destino inmediato, y tiempo para limar lo ya escrito y sin urgencia. Es "pereza activa " lo que reclama. Sobre este punto creo que no cabe ninguna duda. Rodríguez Correa nos permite confirmarlo en el prólogo a la edición de 1871, cuando tras mencionar las reconvenciones que el amigo homenajeado le dirigía "por mis innumerables descuidos y mi prisa por entregarme a la pereza ", añade:

La fecundidad e inventiva de Gustavo eran prodigiosas, y puede decirse que esto perjudicó a la importancia de sus escritos. Su manera de concebir no era embrionaria, sino clara, metódica y precisa, tanto, que a sus imaginaciones sólo faltaba un taquígrafo ; pero encariñado con ellas y no queriéndolas escribir con la precipitación del oficio, sino con el reposo del artista, ibalas dejando para cuando pudiera conseguirlo ${ }^{32}$.

El párrafo es absolutamente iluminador, aunque Rodríguez Correa, lamentablemente, no se queda ahí. El tiempo, viene a decir, no le dio al poeta la oportunidad del reposo artístico, con lo cual, a pesar de esas cualidades, no deja una obra cumplida, sino un gran borrador :

Al extender la muerte su fría mano sobre aquella cabeza juvenil, inteligente y soñadora, mató un mundo de magníficas creaciones, de gigantescos planes, cuyo pálido reflejo son las obras que contiene este libro. Todo su afán era conseguir un año de descanso en la continuada carrera de sus desgracias ${ }^{33}$.

31. Augusto Ferrán, Obras completas, ed. José Pedro Diaz, Espasa-Calpe (Clásicos Castellanos, 164), Madrid, 1969, p. 85. A buen seguro, ambos amigos tejerían numerosos private jokes acerca de su respectivo amor a la pereza. En una carta dirigida por Gustavo a Ferrán leemos estas referencias cómplices : "Querido Augusto : [...] Tú sabes lo que soy para escribir, aunque no tengo pretesto (sic) de ninguna clase que disculpe mi pereza. Figúrate lo que habré hecho teniendo una aldaba a que agarrarme. $[\ldots]_{i}$ Te has tendido en brazos de la pereza y permaneces inmóvil en un rincón, digno pendant de las estatuas de granito de las tumbas de Veruela ? ". (apud Leonardo Romero Tobar, « Nuevos autografos... ", p. 17).

32. * Prólogo * a Obras de Gustavo Adolfo Bécquer, I, Imprenta de T. Fortanet, Madrid, 1871, p. XIX. Utilizo la edición facsimilar, preparada por Cristóbal Cuevas y Salvador Montesa, Obras de Gustazo Adolfo Bécquer (1871), Arguval, Málaga, 1993.

33. Ibidem, p. IX. 
Es fácil colegir que Rodríguez Correa piensa en el poema con que los editores iniciarán la serie de las Rimas. La contraposición de los gigantescos planes con las páginas reales, pálidos ecos del himno ideal, resulta de este modo de una sospechosa literalidad. No obstante su entusiasmo y su bondad, Correa inicia la fijación de la desgraciada leyenda becqueriana : la del "malogrado ", la del perezoso, la del descuidado. En contradicción flagrante con el primero de los párrafos transcritos, insistirá en la imagen etérea del poeta, genial sí, pero tan desaliñado, tan espontáneo...

Los que le conocíamos admirábamos a Gustavo, más por lo que esperábamos de él, que por lo que habia hecho. Puede decirse que todo lo que concibió está escrito al volar de la pluma, sin recogimiento previo de las facultades intelectuales, y entre la algazara de redacciones de periódicos o bajo el influjo de premiosos instantes. Esto mismo, que ve la luz pública tal cual lo hemos hallado, no pensaba él publicarlo sin corregirlo antes cuidadosamente, porque lo había escrito de prisa y como para que no se le olvidasen asuntos e ideas que no le parecian malas ${ }^{34}$.

He ahí la otra cara del boceto becqueriano, tal como lo vamos observando en manos de Rodríguez Correa. Ese supuesto estado incompleto, embrionario, lo llevará a justificar la ordenación de Ferrán y Campillo, y con ella, la de casi todos los futuros editores de las $\operatorname{Rimas}^{35}$. En fin, concluye el amigo y crítico :

Todas las obras que contienen estos dos tomos han sido escritas, como ya he dicho, sin tomarse más tiempo para idearlas que aquel que tardaba en dibujar con la pluma lo que había de describir o ser objeto de su inspiración : y eran de ver los primores de sus cuartillas, festoneadas de torreones ruinosos, mujeres ideales, guerreros, tumbas, paisajes, esqueletos, arcos, guirnaldas y flores ${ }^{36}$.

Todo muy bonito, magníficos bocetos y borradores, pero la conclusión es deprimente. Bécquer no habría dejado una obra sólida y acabada, sino meros tanteos. Podemos estar de acuerdo en que no encuentra el momento de dar por acabado un texto, pero su afán perfeccionista - que eso es, a fin de cuentas - corresponde a un artista joven, con una larga promesa de vida, a pesar de la leyenda. Correa mismo lo expresaba magníficamente, en cita anterior, cuando contraponía « la precipitación del oficio [...] con el reposo del artista ". Y esa actitud será finalmente malinterpretada como prueba de su irregularidad. Muerto, todo el mundo se sentirá con derecho a meter mano en sus manuscritos - y sigue aún hoy metiéndola...

La tentación del fuego, repetiré... Narciso Campillo escribiría ya muy tarde, en 1894, acerca de aquella revisión inicial de los últimos días de 1870 y primeros del 71 : « Reunidos ambos [Correíta y yo] revisábamos por las

34. Ibidem, p. XVI.

35. Las circunstancias de la corrección y ordenación de la obra en la edición de 1871 son bastante conocidas en la actualidad, aunque subsiste la duda y la polémica - prácticamente irresoluble con los datos disponibles - acerca del grado de intervención de Ferrán y Campillo en la impresión final del manuscrito del Libro de los gorriones. Vid. la bibliografía que se recoge en nuestra nota 48 , a la que puede sumarse, entre otros, Luis Rosales, “ El libro de los gorriones \#, Boletin de la Real Academia Española, 67 (1987), p. 37-54, y "Las cruces de Bécquer ", $A B C$, sábado 30 de mayo de 1987, p. 47, además de los artículos de Rafael Montesinos recogidos en su libro La semana pasada murió Bécquer. El Museo Universal, Madrid, 1992.

36. Op. cit., p. XX. 
noches los papeles del difunto poeta sevillano, eligiendo lo que se merecía y quemando lo que no juzgábamos digno de su pluma ${ }^{37}$. Cuarenta años más tarde - en 1908 y en Soria -, don Antonio Machado recibirá como regalo de bodas del "segundo marido de la madre de la mujer de Bécquer " dos autógrafos inéditos. No tiene dudas : eran algo « que seguramente Bécquer no hubiera publicado ". ¿ Por qué no creerlo ? Don Antonio, que era ante todo poeta - y no filólogo profesional -, afirma sin cortarse un pelo : Yo las quemé en memoria y en honor del divino Gustavo Adolfo " ${ }^{38}$. Más cerca aún de nosotros, en 1943, otro poeta y profesor desplazado en Soria, Gerardo Diego, nos negaba dos autógrafos becquerianos con argumentos parecidos ${ }^{39}$.

¿Qué opinaría el propio Gustavo ? Sería fácil acabar con alguna cita suya bien seleccionada, en gesto de devolución de la palabra - de su palabra - a quien tanto bregó con ella. Pero sería tentación literaria hacerlo. Los protagonistas de esta historia, Gustavo y su albacea Ferrán, andan por tierras de ultratumba. (Campillo solamente le servía de fontanero.) Sin embargo...

\section{IV. - ALGO MÁS QUE UNA NOTA FINAL (U OTRA VUELTA DE TUERCA)}

No quisiera que las páginas siguientes se lean como punto de llegada o conclusión del artículo. He ofrecido hasta aquí una reflexión cerrada sobre el sentido que para Bécquer mismo tenían bocetos y borradores, lo que he llamado su " estética del borrador ", pero queda un aspecto - un problema insoslayable.

Escribía yo ahí atrás : «El libro mayor de la lírica española decimonónica se quedó en estado de borrador - aunque esto disguste profundamente a los sucesivos editores del texto. " Es un borrador en limpio, pero sigue siendo un borrador. La prueba está en que sus editores no lo respetan en su estado definitivo e irremediable.

37. Narciso Campillo, « Breve noticia biográfica ", La llustración Española y Americana, 30 de mayo de 1894. Tomo la cita de Rafael Montesinos, La noche pasada..., p. 61.

38. Antonio Machado, Los complementarios, en Poesia y prosa, III. Prosas completas (1893-1936), ed. Oreste Macrì, Espasa-Calpe (Clásicos Castellanos Nueva Serie, 13), Madrid, 1988, p. 1260. Por cierto, ¿ no " salvaría " don Antonio dicho texto y los propios remordimientos bajo el disfraz de un heterónimo ? ¿Cuál mejor, entre ellos, que Tiburcio Rodrigálvarez (1838-1908), supuesto amigo de Gustavo y autor del fragmentario - y anodino - romance que comienza * Era la mayor Clotilde... * ? (p. 1272-1273).

39. * Alguna o algunas (rimas) mejor hubiera sido dejarlas inéditas como sin duda lo habria hecho el poeta a tener tiempo de disponer él mismo su testamento lírico a la posteridad. A mis manos ha llegado también, y por el mismo conducto que esta Gota de rocio, otra composición en verso conservada en dos variantes autógrafas y que yo no me creo en derecho a imprimir. Si cualquier persona, aunque sea poeta, y admirable poeta, tiene derecho a desahogar en verso y para uso familiar o individual su intimidad herida, esto no quiere decir que tales documentos privados, por el simple hecho de su forma métrica, puedan lícitamente ser publicados si no contribuyen a esclarecer siquiera matices de su talento de artista poético o de artífice métrico, o al menos a iluminar puntos obscuros de su biografía " ( Una rima inédita de Bécquer ", La Nación, 7 de marzo de 1943). Tomo yo la cita de Robert Pageard, * Introduction $n$ a su edición de Rimas de Gustawo Adolfo Bécquer, CSIC (Clásicos Hispánicos), Madrid, 1972, p. 28. Un comentario del mismo o parecido tenor, en Luis Rosales, « El libro de los gorriones \#, p. 41. 
Y esto es, en sí, una paradoja que sigue sin aclararse.

Resulta sorprendente - o me resulta a mí, precisaré - encontrar este argumento como justificación de las ediciones críticas de las Rimas basadas, no solamente en las dudosas variantes textuales de 1871, sino en su misma ordenación. No es exactamente el caso, pero léase lo que aducen Cristóbal Cuevas y Salvador Montesa en su utilísima y bien enmarcada edición facsimilar de la princeps :

En cualquier caso conviene recordar que esas divergencias [del manuscrito] no redundan necesariamente en perjuicio de la credibilidad filológica de la editio princeps, pues Gorriones es un autógrafo provisional que reconstruye "de memoria " un poemario perdido, sin que constituya en modo alguno un original definitivo con vistas a su publicación. Así lo demuestra el tono lúdico con que anuncia (p. 3) su contenidoto.

De la " memoria " becqueriana ya hemos hablado y hablaremos, y de cómo esa memoria no es etérea, sino que se apoya en papeles, cuadernos de notas, bocetos. Incluso hemos discurrido acerca del " tono lúdico " de todos esos papeles. Que no sea un original definitivo, dejémoslo de momento en opinión - olvidando la obviedad de su muerte en 1870 -, hasta oír la muy autorizada de Luis Rosales :

Esto nos asegura que el manuscrito de El libro de los gorriones no era tan sólo un manuscrito, sino, más bien, un manuscrito, preparado por Bécquer, para mandarlo a la imprenta. [...] Los versos que no le habian salido bien, los versos irresponsables, los señaló con una cruz para condenarlos y corregirlos. $\mathrm{Y}$ los corrigió, antes de entregar el manuscrito, al mismo tiempo que corregía la ortografía o, al menos, la intentaba corregir, como enseguida vamos a ver. Es decir, que El libro de los gorriones había quedado preparado por el propio Bécquer para editarlo, y a eso obedecen las enmiendas. Más claro, agua ${ }^{41}$.

¿Lo es tanto? Al menos, de acuerdo con Rosales, el texto del manuscrito podría pasar por definitivo, o parece definitivo. Si atendemos a la pulcritud casi geométrica con la que está trazado, incluso con la que está corregido, podemos pensarlo. Y si la suposición de Rosales es aceptable - y lo es -, ¿ por qué, entonces, no respetar esa última voluntad, subrayada de modo irrefutable por la muerte ? Claro que el propio Rosales, en aparente contradicción, confesaba al final de su artículo que lo había escrito en defensa de las correcciones de 1871, que él mismo atribuía a Campillo en el texto y a Ferrán en la nota final : "En fin, la suerte los ha unido. Ya es muy difícil separar en las Rimas las correcciones de Bécquer y las de los editores. Están unidas, indisolublemente, por la historia ${ }^{42}$. " Por una edición póstuma, mejor sería decir.

40. " Introducción * a la ya citada edición facsimilar de Obras de Gustano Adolfo Bécquer (1871), p. XX. 41. Luis Rosales, "El libro de los gorriones ", p. 44. Vuelve sobre la misma idea en varios momentos diferentes de su articulo.

42. Ibidem, p. 54. 
Ahí está, por otra parte, el punto de inflexión, que plantea con tozudez dos problemas textuales de diferente calado, aunque sujetos a la misma lógica : las variantes respecto al manuscrito - en lo que no voy a entrar - y la dispositio de los poemas con arreglo a criterios temáticos, básicamente biográficos.

Por supuesto, cosa diferente a la " credibilidad filológica " - y cosa perfectamente legítima y hasta defendible -, es que se respete un determinado canon textual asentado históricamente en su transmisión y recepción continuada desde el momento de su descubrimiento. Eso son las rimas para generaciones de lectores, y acaso valga la pena respetarlo. Por ahí se mueve, creo yo, la opinión final de Rosales. Es una opción editorial incluso sentimental - razonable, respaldada por un amplio consenso de lectores, y que parte de su soberana libertad para leer los textos como les dé la real gana. Vaya eso por delante.

Ahora bien, cuando de "credibilidad filológica " se trata, debe darse por sentado que nos apoyamos sobre otro consenso diferente. No voy a detenerme en el hecho de que un libro de poemas, en la consideración de la teoría literaria actual, no es una mera suma incoherente de textos dispares, considerados aisladamente, sino un macrotexto compuesto por textos cuya autonomía parcial debe ser en todos los casos sopesada ${ }^{43}$. Los modos de articulación podrán ser muy variados, desde el paradigma del cancionero de Petrarca, diseñado sobre un argumento amoroso, hasta la simple recopilación de textos de autor con procedencia o transmisión diversas, como podría ser el caso de las muy heterogéneas Poesías (1840) de Espronceda, donde aun así se procede a una redistribución del material de acuerdo a diferentes criterios, fuese o no voluntad del propio autor. En cualquiera de esos casos, el efecto de lectura confiere sentido al orden dado : el poema inicial o el poema final tienen una especial incidencia sobre el conjunto de los poemas, la agrupación por temas refuerza sus significados parciales, etc. ${ }^{44}$

En nuestra tradición inmediata, contemporánea, el libro de poemas tiende a ser un todo homogéneo, articulado mediante una armonización formal y temática, con un tono y unos contenidos generalmente definidos desde el título individualizador. Por esa razón, cuando Bécquer ocupa media página 535 de su Libro de los gorriones con el único texto «Rimas / de / Gustavo Adolfo Becquer ", define con ese título un modelo alejado de otros proyectos suyos, incluso de poemas suyos contemporáneos y accesibles para él en ese año 1868 - como "A todos los santos $"^{45}$. Cualquier reordenación temática

43. Tengo presente, cuando escribo estas líneas, los argumentos y la terminología utilizados por Cesare Segre, Principios de análisis del texto literario, Crítica, Barcelona, 1985, especialmente el apartado «Macrotexto $n$, p. 47-49.

44. Véase, en Cesare Segre: "La coherencia del texto es considerada dentro de una progresión en la que la fase posterior asimila a la anterior. Es decir que cada texto mantiene en general autonomía y cohesión internas, pero queda después comprendido en una autonomía y cohesión más amplias. La relación proporcional entre los dos tipos de cohesión puede variar, según sea más o menos rígida la estructura del macrotexto $n$ (ibidem, p. 49).

45. Incluso frente a quienes editan el entero Libro de los gorriones como alternativa a las tradicionales Rimas en ordenación apócrifa. 
de ese material - se encuentre en el estado en que se encuentre - afecta a los contenidos textuales del macrotexto realmente existente, tout court. No digo que sea mejor o peor, que resulte más o menos efectivo, sino que es sencillamente otra cosa. Eso es lo filológicamente relevante y eso es lo filológicamente correcto.

Quien sí tenía muy claro lo que acabo de escribir era el mismísimo Ramón Rodríguez Correa, editor consecuente, al fin y al cabo. Basta leer los párrafos finales del prólogo a la edición de Fortanet (1871) para entender cuál es la idea que preside la forzada reordenación del poemario original : « Todas las Rimas de Gustavo forman, como el Intermezzo de Heine, un poema, más ancho y completo que aquel, en que se encierra la vida de un poeta $a^{40}$. "Vida de poeta - malogrado, perezoso - : ese hilo argumental es, se mire como se mire, el tan alabado orden tradicional y, en consecuencia, ésa es también la única demostración - negativa, artificial - del desorden del manuscrito ${ }^{47}$.

A ese planteamiento editorial aún se opone un argumento complementario, y creo que nada desdeñable. Bécquer, como se ha visto, diferenciaba con tozudez entre la esfera privada, biográfica, y la pública y objetiva representada por los poemas impresos. Es algo confirmado por su resistencia a publicar poemas sueltos que pudieran inducir a lecturas en clave íntima. Incluso cuando se decide a publicar esos poemas en libro, no dejará de tachar el más comprometido para su persona. ¿Cómo iba él a admitir, por mucho romanticismo que aún arrastrase, una disposición de los textos tendente a confundir expresión literaria con itinerario biográfico?

No se puede continuar afirmando que la ordenación original no tiene orden, aunque sólo sea por lógica. Aunque su orden fuese azaroso, cuidémonos nosotros de imponérselo artificialmente. Y si no, ¿ quién se atrevería a afirmar en voz alta que el autor se equivocaba al dar el suyo ? Las rimas ajustadas a un argumento fluido, a modo de cancionero, temáticamente coherentes, con su doble numeración, el poema introductorio en su justo lugar y todo lo demás, son un invento póstumo. De dudoso gusto, todo hay que decirlo. Para no mencionar las variantes no justificadas documentalmente, que al lado de esto son letra pequeña ${ }^{48}$.

46. Op. cit., p. XXXII. La cursiva es mía.

47. O dicho a fogonazos: "Son primero las aspiraciones de un corazón ardiente que busca en el arte la realización de sus deseos, [...] vuélvese espontáneamente hacia el amor [...] y goza un momento y sufre y llora [...] Anúnciase esta nueva fase en la vida del poeta [subrayado mío] con la magnífica composición [...] Los invisibles átomos del aire [...] Piensa [...] en los solos que se quedan los muertos [...] Se enamora de la estatua de un sepulcro [...] Tal fue Gustavo A. Bécquer como hombre y como poeta [subrayado mio] en lo que puede apreciar el público n (ibidem, p. XXXIII-XXXV). Pero del orden de ese orden y de sus varios sentidos se ha escrito ya mucho. Véase ahora un buen resumen del estado de la cuestión en Cristóbal Cuevas y Salvador Montesa, op. cit., p. XXIII s.

48. También en esto podria aplicarse una lógica inflexible. Nada serio hace dudar de la autoría de Bécquer en las variantes del manuscrito, entre otras razones, por las obvias de tiempo y situación, tal como han defendido casi todos los críticos recientes y como yo mismo creo. Basta con eso para hacerlas cuando menos aceptables. En cambio, no hay un solo argumento objetivo que autorice como del autor las variantes exclusivas de la princeps, aunque pudieran sonamos mejor. Más claro, el agua, que diría Rosales. Mientras no se demuestre lo contrario. $Y$ aún no se ha demostrado. 
La polémica es vieja, pero hace tiempo que no se aviva. Por el contrario, las últimas - y aun valiosas - ediciones de las rimas continúan alterando la distribución, buena o mala, pero definitiva, que el poeta quiso dar, dio y dejó dada a sus poemas. Si no me equivoco, la última edición crítica que respeta el orden original de Bécquer fue la de la profesora María del Pilar Palomo, y hace de eso ya veinte años. En la justificación introductoria, esta editora recapitulaba :

Casi todas las ediciones modernas, si bien siguen la disposición fijada en 1871, suelen consignar ese número de orden con que aparecen en el manuscrito. Sin embargo, estoy plenamente de acuerdo con Antonio Alatorre, cuando afirma : "Una buena edición no debiera vacilar en volver al orden - o desorden, si se quiere - que las poesías guardan en el Libro de los Gorriones... * A continuación, Alatorre aduce el juicio a tal respecto de Rubén Benítez y Rafael de Balbín, que afirman algo a mi entender fundamental : la situación de las rimas en el orden tradicional ha tergiversado en más de una ocasión el significado de las mismas ${ }^{49}$.

Rubén Benítez, sin embargo, se nos ha echado atrás cuando le ha llegado la oportunidad de editarlo de acuerdo a los criterios defendidos por él mismo, allá a comienzos de los sesenta :

No me he animado a alterar el orden corriente de las Rimas, según lo establecieron los amigos de Bécquer, porque podría crear dificultades a los estudiantes ; pero los incito a hacer una lectura siguiendo el orden del manuscrito, que indico en cada caso entre paréntesis. Las Rimas adquirirán así cierto carácter de cancionero lírico, sin la rígida determinación de asuntos que los amigos les imponen ${ }^{5}$.

La lectura del libro, como se ve, queda en términos dignos de la Rayuela de Cortázar. Otro ilustre becquerianista, Russell P. Sebold, no solamente se reafirma en la ordenación póstuma, sino que arremete con cierta agresividad contra sus invisibles - hoy por hoy - oponentes :

En la ordenación de las rimas individuales sigo el orden tradicional establecido por los amigos del poeta. A estas alturas resultaría absurdo hablarles a los amantes de la poesía de Bécquer de la rima 38, "Volverán las oscuras golondrinas n, cuando todo el mundo sabe que ésta es la rima LIII' ${ }^{51}$.

49. María del Pilar Palomo, * Introducción * a su ed. cit, Libro de los gorriones, p. LV. Continúa la cita : * Estimo, también con Alatorre, que existe un desorden en el Libro. De acuerdo. pero ese desorden no originará confusionismos interpretativos. $\mathrm{Y}$, por otra parte, es muy digno de tenerse en cuenta que en ese desorden no ha faltado tampoco el intento de construir un nuevo orden - sin alterarlo-, como realiza Guido Mancini, muy sugerentemente, al estudiar la continuidad y coherencia del "cancionero" becqueriano ", ibrdem, p. LV-LVI). Para las referencias de Palomo, vid. : Antonio Alatorre, "Sobre el texto original de las Rimas de Bécquer. (A propósito de la edición de J. P. Díaz) \#, Nueta Retista de Filología Hispánica, 19 (1970), p. 401-417 ; Rubén Benitez, "Notas para una edición de las Rimas de Bécquer ", en Ensayo de bibliografía razonada de Gustavo Adolfo Bécquer, Universidad de Buenos Aires, Buenos Aires, 1961, p. 130-146; Rafael de Balbin, * Sobre la influencia de Augusto Ferrán en la Rima XLVII de Bécquer ", Revista de Filología Espanola, 26 (1942), p. 319-334 ; Guido Mancini, * Note per una interpretazione della lirica di G. A. Bécquer $*$, Studi Ispanici, 1 (1962), p. 99-126. Escrito este trabajo, leo una nueva aproximación de Alatorre, en la que vuelve a la carga para defender, junto al orden original, y de modo más radical incluso, el texto no corregido : a Notas. De nuevo sobre el texto de las Rimas de Bécquer ", Nueza Revista de Filología Hispánica, 44 (1996), p. 149-154.

50. Rubén Benítez, « Introducción * a su ed. de Gustavo Adolfo Bécquer, Rimas.Leyendas escogidas, Taurus (Clásicos Taurus, 4), Madrid, 1990, p. 45.

51. Russell P. Sebold, * Introducción * a Gustavo Adolfo Bécquer, Rimas, Espasa-Calpe (Clásicos Castellanos Nueva Serie, 22), Madrid, 1991, p. 153. 
Acaso todo el mundo lo sabe, excepto el propio Bécquer... La conservación de los números arábigos tras los romanos tendría como finalidad revelar - o denunciar - « el orden irracional y caótico - como la mayor parte de los procesos mentales humanos - en que Gustavo iba recordando las rimas individuales $"^{52}$. En fin, el mismísimo poeta, acaso consciente de su errático comportamiento, habría auspiciado tal reordenamiento al marcar con una críptica raya en el índice la que sería rima I. Llegados aquí, Sebold ya no se arredra ante nada :

Lo reitero, insisto en ello : el orden de los poemas en el Libro de los gorriones no representa en modo alguno una decisión estética de parte de su autor. $[\ldots]$ ¿ Y qué esfuerzo cuesta suponer que Gustavo pudo comunicarle a uno de sus amigos especialmente a Correa, que comprendía tan bien su alma y sus principios estéticos - un esquema, si no igual, al menos muy semejante a éste ?53

Cuando escribo esto, la última edición aparecida es la de Montesinos, tan esperada. Pero él, que tan tenazmente ha perseguido el espíritu de Gustavo hasta las fronteras del otro mundo y que tanta información nos ha acarreado durante las últimas décadas, se instala de modo decidido en las mismas posiciones :

Se ha hablado mucho del orden de las poesías en el manuscrito. No hay tal orden. Los versos van regresando - aunque no todos - a la memoria del hombre que de memoria los compuso. [...] En cuanto al orden de las Rimas, es más lógico temáticamente, el de la edición príncipe, el tradicional, aunque algunos lo rechacen y hasta hayan ordenado por su cuenta. Nuestra edición, por lo que se refiere al orden de las Rimas - sólo al orden -, sigue el establecido por Ferrán (Fortanet, 1871) ${ }^{\mathrm{s}}$.

¿No revela algo esa insistencia que conduce a la precisión final, « sólo el orden " ? Y Montesinos da incluso un paso - $i$ adelante ? - cuando suprime de modo radical y sin advertencia cualquier referencia a la numeración original, incluidos los tradicionales números arábigos entre paréntesis ${ }^{55}$.

Creo, de todos modos, que también en nuestro caso la lógica resulta buena aliada de la filología. Aun cuando el sentimiento nos haga parecer más grande, más hermoso, figurarse al genio ebrio de sensaciones y de inspiración, trazando a grandes rasgos sobre el papel aquellas tiradas de versos irremediablement perdidos y que ahora regresarían poco a poco. A Bécquer, como ya hemos observado aquí, le gustaba aprovechar el papel cuando estaba "rescatando " versos de su memoria. Le vencía la tentación

52. Ibidem.

53. Ibidem, p. 154.

54. Rafael Montesinos, "Introducción " a su ed. de Gustavo Adolfo Bécquer, Rimas, Cátedra (Letras Hispánicas, 31), Madrid, 1995, p. 62-63 y 64. Palabras semejantes escribía en su libro ya citado La semana pasada...

55. En franca contradicción con su cita anterior, escribe también en las páginas justificatorias de su edición - y ahora sí - con absoluto acierto : « Rechazo como apócrifas las correcciones que no aparecen en el manuscrito becqueriano y que figuran en la edición príncipe (Madrid, Fortanet, 1871). Dichos retoques, aunque en algunas ocasiones mejoren la lección del verso, no se deben a la mano de Bécquer, y no puedo permitir que a un poeta se le corrija su trabajo. Y mucho menos después de muerto $n$ (ibidem, p. 93). Pues eso... 
de trazar un perfil de hombre, una figura femenina, el esbozo de una escena dramática, un esqueleto danzante... Es fácil imaginar que el movimiento de la pluma sobre el papel arrastraría con mayor facilidad los versos rebeldes. $Y$ los versos se entrelazan con rúbricas e infinidad de variantes, hasta la última esquina libre. Pero esa etapa ha quedado atrás, de modo nítido, cuando transcribe a limpio en el libro de cuentas.

También tenemos la certeza documental de que aquellos borradores previos, incluso los de su primerísima juventud, no solían acabar en la papelera. Por el contrario, los repartía generosamente entre sus allegados, o éstos - familiares, amigos, colegas - los heredaron en el expurgo final y a lo largo de los años siguientes los fueron publicando o regalando a su vez en largo goteo. ¿Cuántos de esos borradores no se conservarían, entonces, en sus propias carpetas ${ }^{56} \mathrm{Si}$ ello es así, y admitida la pérdida de un determinado manuscrito preparado para imprenta, ¿ por qué deberíamos suponer la pérdida de los poemas mismos? Es mucho más sencillo interpretar la frase " poesías que recuerdo del libro perdido " como intento de reconstrucción del manuscrito desaparecido, aquel concreto, y no como un rescate mental de poemas absolutamente perdidos.

Téngase en cuenta que, si no me equivoco, el único testimonio existente sobre esa novelesca recuperación ex nihilo procede de Narciso Campillo : "Con ímprobo trabajo consiguió el poeta ir recordando y transcribiendo sus composiciones $n^{57}$. Y sobre la veracidad de Campillo hay algo más que dudas, como se puede comprobar en Rafael Montesinos. Es más, en otro texto y contexto, Montesinos ha descubierto con agudeza cómo Campillo se inventaba anécdotas fantásticas a partir de frases del propio Bécquer. Así es como transformó aquella frase - publicada - de la Introducción sinfónica, « tal vez muy pronto tendré que hacer la maleta para el gran viaje ", en la que supuestamente le habría dicho Gustavo cinco meses antes de su muerte : " Estoy haciendo la maleta para el viaje. Dentro de poco me muero. (Esto lo dijo como quien dice "buenos días") " ${ }^{58}$. ¿ Por qué no iba a hacer lo mismo con la sugerente frase " poesías que recuerdo del libro perdido " ?

Y no sólo eso, ya que se trataría de un sorprendente rescate en limpio, contenido en su presentación gráfica, sin apenas arrepentimientos y hasta

56. Según mis propias cuentas de la vieja, sumando tanto los poemas publicados antes de 1871 como los posteriores no incluidos en esa edición, más los manuscritos sueltos que hoy conocemos, podría disponer en su gabinete de casi unos treinta poemas, más o menos, aunque no todos fueran " recordados $*$. Y estamos hablando de los restos de un naufragio...

57. La llustración de Madrid, 15 de enero de 1871. Recogido en la citada ed. de Cabra Loredo, La llustración de Madrid..., p. 216. Otra referencia de un testigo directo, si bien expresada muy tardfamente - en 1922 -, es la de Francisco de Laiglesia, quien se limita a señalar que Bécquer reunió * la colección de sus rimas $[. .$.$] en un cuaderno, que se perdió en la vista tumultuaria que hicieron las turbas al$ domicilio del ministro cafdo $n$, sin estimar de interés - y ello es en sí reseñable - cualquier referencia al supuesto rescate de memoria. Vid. Francisco de Laiglesia, " [La contemplación de Gustavo] ", en Russell P. Sebold, ed., Gustavo Adolfo Bécquer, Taurus (El Escritor y la Crítica), Madrid, 1982, p. 73.

58. Vid. "Las "fantasías póstumas" de Campillo ", en la semana pasada..., p. 49-80, y en concreto, las $62 \mathrm{~s}$. 
cuidadosamente enmendado, es decir... listo de nuevo para imprenta ${ }^{59}$. Del mismo modo, y voy concluyendo, parece muy rebuscado suponer que un simple y solitario guión, puesto en el índice junto a la rima 11, revelaría la voluntad de reordenación póstuma, como quiere Sebold. Por el contrario, el argumento definitivo, tal como yo lo concibo, viene dado por ese mismo índice, en su inmediata totalidad, en su desnuda evidencia. En él, cada poema lleva a la izquierda, no un trazo, sino una bien visible numeración consecutiva, perfectamente caligrafiada y sin enmiendas, en limpias columnas encabezadas por el texto « $\mathrm{N}^{\circ}$ de las rimas ". Eso es orden, desde luego, y ése es el orden, su orden, el de Bécquer.

El borrador estaba a punto de dejar de serlo ${ }^{60}$.

59. Pageard, a pesar de insistir en la idea del a desorden temático $*$ y de que, * supliendo al poeta difunto, sus amigos pusieron orden en las Rimas ", escribe : "La palabra "recuerdo" deja entender que Bécquer escribió las rimas de memoria. Es posible porque tenía una memoria prodigiosa. El fenómeno es sin embargo extraordinario si se considera que la mayor parte de los poemas fueron escritos impecablemente, sin vacilaciones ni tachaduras y dispuestos sobre las hojas del registro en agradable orden [sic]. Se debe suponer más bien que la palabra "recuerdo" es ligeramente inexacta, y que Bécquer disponía de los primeros manuscritos (tarjetas de visita, hojas de dibujo, hojas sueltas diversas) para ayudarse en la reconstitución del conjunto * (Robert Pageard, * Introducción * a su ed. cit., p. 2 y 24).

60. Ya en pruebas este trabajo, parece obligada la referencia a los reencontrados álbumes de Julia Espín, que nos ha acercado ahora Jesús Rubio Jiménez, $\propto$ Pintura y literatura en G. A. Bécquer. Los álbumes de Julia Espín ", recogido con amplia documentación gráfica en el catálogo La España romántica (1830-1860). El album de Julia Espin de Gustano Adolfo Bécquer, Guillermo de Osma Galería, Madrid, 1997. Yo mismo he perseguido esos álbumes, pertenecientes a los esquivos -digámoslo asidescendientes gallegos de Julia Espín, sin que, como se ve, haya podido llegar más allá del umbral del pazo. En cualquier caso, los álbumes que gracias a Rubio Jiménez podemos ver por fin parecen reforzar cuanto aquí he escrito acerca de la relación entre escritura y plástica en los borradores becquerianos. 